Nuntius Antiquus, Belo Horizonte, Universidade Federal de Minas Gerais, $n^{0}$ 1, junho de 2008, Brasil

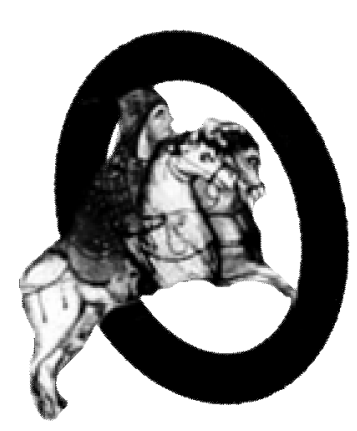

\title{
A morte de Laocoonte e o Gigante Adamastor: a écfrase em Virgílio e Camões
}

\author{
Bianca Fanelli Morganti \\ Doutoranda DTL/ IEL-UNICAMP \\ e-mail: biancamorganti@yahoo.com.br
}

\begin{abstract}
Ekphrasis or euidentia is an important picture of affection which plays a significant role in poetry. This vivid and detailed description of an object or action makes what is being described emerge in order to provoke readers' emotions, moving their passion through poetical representation. The article presents some of the linguistic resources used to build this affective picture in two different episodes of two epic poems: Aeneid by Virgil and Os Lusíadas by Camões.

KEYWORDS: rhetoric; ekphrasis; epic poetry; Aeneid; Os Lusíadas.
\end{abstract}




\title{
A morte de Laocoonte e o Gigante Adamastor: a écfrase em Virgílio e Camões
}

\author{
Bianca Fanelli Morganti \\ Doutoranda DTL/ IEL-UNICAMP \\ e-mail: biancamorganti@yahoo.com.br
}

\begin{abstract}
Ekphrasis or euidentia is an important picture of affection which plays a significant role in poetry. This vivid and detailed description of an object or action makes what is being described emerge in order to provoke readers' emotions, moving their passion through poetical representation. The article presents some of the linguistic resources used to build this affective picture in two different episodes of two epic poems: Aeneid by Virgil and Os Lusíadas by Camões.
\end{abstract}

KEYWORDS: rhetoric; ekphrasis; epic poetry; Aeneid; Os Lusíadas.

É vasto o campo semântico abarcado pelo termo ékphrasis. Atualmente encontramos este vocábulo referindo-se, mais freqüentemente, à descrição literária de um trabalho de arte. A épica está repleta deste tipo de écfrase, basta que nos lembremos da descrição do escudo de Aquiles feita por Homero na Ilíada, ou do templo de Cartago na Eneida, ou ainda da exposição das bandeiras feita por Paulo da Gama n'Os Lusíadas, para citar apenas alguns poucos exemplos.

No entanto, a extensa área de referência do termo envolvia, na consuetudo poética e retórica, um sentido mais amplo: tratava-se de uma descrição verbal viva e detalhada de uma pessoa, lugar, acontecimento ou objeto que, produzindo um forte efeito visual e sonoro, causasse um conseqüente impacto emocional nos ouvintes daquele discurso. A écfrase é, então, uma figura destinada à produção de afetos, o que equivale, como se sabe, não à expressão natural de um afeto real, mas à manifestação ficcional de um afeto por meio de recursos técnicos.

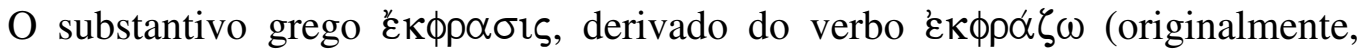
explicar tudo longamente, expor em detalhe; e por extensão de sentido, descrever), foi traduzido pelo termo latino descriptio. O emprego da $\varepsilon^{\prime} \kappa \phi \rho \alpha \sigma \iota \varsigma$ ou descriptio tem como objetivo primeiro a produção, por meios discursivos, daquilo que Aristóteles chamou

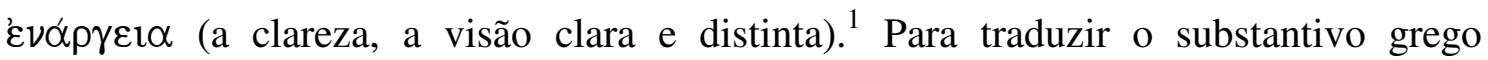

\footnotetext{
${ }^{1}$ Cf. Aristotle. Ars rhetorica. Recognouit breuique adnotatione critica instruxit W. D Ross. Oxford: University Press, 1959, III 1410b.
} 


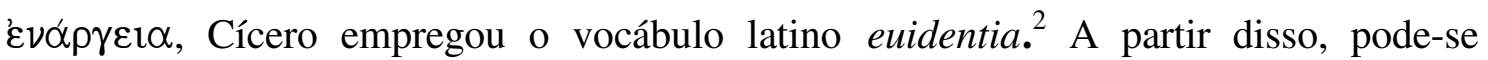

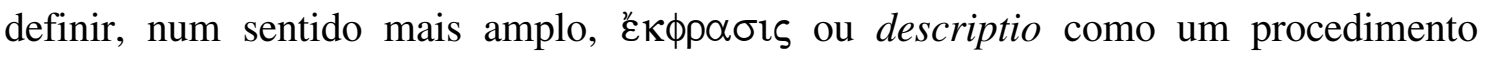
verbal que, transformando o ouvinte ou leitor em espectador ou testemunho ocular, submete-o à visão detalhada de um objeto, pessoa, lugar ou acontecimento, a partir da decomposição e descrição das suas particularidades sensíveis, reais ou inventadas pela fantasia.

Quintiliano, no livro IX das suas Instituições Oratórias, assim define a descriptio, subordinando-a à euidentia: Illa vero, ut ait Cicero, sub oculos subiectio tum fieri solet, cum res non gesta indicatur, sed ut sit gesta ostenditur, nec uniuersa sed per partes. Quem locum proximo libro subiecimus euidentiae, et Celsus hoc nomen isti figurae dedit. $^{3}$

Mais tarde, Hermógenes, autor que exerceu grande influência nos séculos imediatamente posteriores ao seu, assim como nos séculos XVI e XVII, define a écfrase nos seguintes termos:

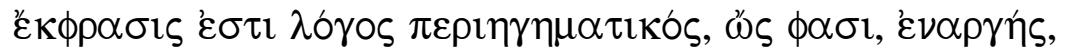

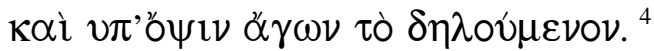

E ainda o gramático latino Prisciano: Descriptio est oratio colligens et praesentans oculis quod demonstrat. ${ }^{5}$

Nota-se, portanto, a existência de uma relação intrínseca entre a descrição

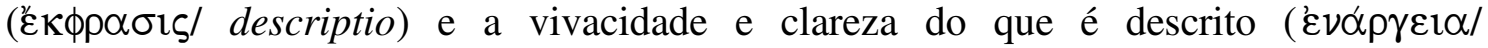
euidentia). É esta vivacidade do discurso que gera a impressão de que o fato está acontecendo diante dos olhos do leitor, e o coloca, portanto, numa situação de testemunho ocular do que é narrado. Para criar esta atmosfera, o poeta dispõe de

\footnotetext{
${ }^{2}$ Cf. Cicero. De partitione oratoria. With an English translation by H. Rackham. Cambridge, Mass./ London: Harvard University Press, 1977, XX; ainda, Ernout, A.; Meillet, A.Dictionnaire étymologique de la langue latine. Paris: Klincksieck, 1967.

3 Cf. Quintilien. Institution oratoire. Texte revu et traduit, avec introduction et notes, par Henri Bornecque. Paris: Garnier, s.d., IX 2, 40: "De fato, aquela figura, como afirma Cícero, costuma efetivar-se quando a coisa é lançada sob os nossos olhos, não quando nos indica o fato simplesmente, mas de tal modo que o exponha diante dos nossos olhos; não de forma geral, masem detalhes. Esta figura, no último livro, subordinamos à euidentia, e este foi o nome que lhe deu Celso" (minha tradução).

${ }^{4}$ Cf. Lausberg, Heinrich. Manual de retorica literaria. Madrid: Gredos, 1975. Tomo II, p. 225 (citando Progymnasmata 10, de Hermógenes, em minha tradução: "Écfrase é o discurso descritivo, como se diz, claro e manifesto, e que expõe ante os olhos o que se quer mostrar".).

${ }^{5}$ Cf. Lausberg, op. cit., p. 225 (citando Praeexercitationes 10, de Prisciano, em minha tradução: "A descrição é um discurso que reúne e torna presente aos olhos aquilo que demonstra”.).
} 
diversos meios técnicos colocados à sua disposição pela linguagem, e utiliza-os conforme as circunstâncias.

A produção da clareza e da vivacidade discursiva, isto é, da euidentia, exerce sobre o espectador um efeito de realidade que move os seus afetos, influenciando, portanto, os seus julgamentos. Na perspectiva retórica aristotélica, as paixões são valiosos instrumentos de que dispõe o orador para a obtenção da persuasão; para isso, é absolutamente necessário que ele seja capaz de distinguir a disposição em que se encontra o "afetado" pela paixão, contra o que ou quem habitualmente se "afeta" e por quais motivos. Com essas coordenadas, o orador é capaz de criar e controlar toda uma situação discursiva capaz de mover os afetos do seu auditório no sentido que convém aos fins pretendidos.

As duas écfrases escolhidas para este artigo têm em comum a produção de um mesmo afeto, o temor. O primeiro episódio é freqüentemente referido como "A Morte de Laocoonte", e encontra-se no livro II da Eneida de Virgílio, obra modelar de todo o costume épico. O segundo é um dos episódios mais conhecidos e comentados pela fortuna crítica camoniana, e tem lugar no canto V d'Os Lusíadas de Luís de Camões: trata-se da aparição do Gigante Adamastor.

Sobre o temor, diz Aristóteles no livro II da Retórica:

Seja então o temor certo desgosto ou preocupação resultantes da suposição de um mal iminente, ou danoso ou penoso, pois não se temem todos os males, por exemplo, o de que alguém se torne injusto ou de espírito obtuso, mas sim aqueles males que podem provocar grandes desgostos ou danos; e isso quando não se mostram distantes, mas próximos e iminentes. ${ }^{6}$

Sendo assim, para a construção de descrições capazes de manifestar no público, por intermédio da ficção, esse afeto, é necessário que os poetas saibam o que é temível. Conforme foi visto há pouco, são temíveis as coisas dotadas de capacidade de arruinar ou causar danos; também os indícios destas coisas são temíveis, pois indicam a proximidade do perigo, e o que está próximo e iminente causa temor. Ainda para a produção deste afeto, é preciso que o poeta conheça a disposição daqueles que temem; e sendo o temor acompanhado da expectativa de ocorrência de um mal aniquilador, apenas aqueles que crêem na possibilidade de que possam sofrer algo sentem medo. 
Mas, por outro lado, são tomados por este afeto apenas aqueles que, a despeito do perigo, têm alguma esperança de salvação, porque o temor os torna aptos a deliberar e, certamente, não se delibera sobre questões sem esperança. A partir disso, preceitua-se que quando for adequado que os ouvintes sintam temor, é preciso que o poeta os coloque nessa disposição, mostrando-lhes que são passíveis de sofrer algum mal, pois outros mais fortes ou mais virtuosos do que eles sofreram; e devem mostrar-lhes também que pessoas semelhantes a eles sofrem ou sofreram essas provações por parte de quem não imaginavam, e em circunstâncias inesperadas. Tendo isso em vista, passemos à análise da prática poética de Virgílio e Camões.

A écfrase virgiliana está inserida na narrativa sobre a queda de Tróia que Enéias faz à rainha Dido de Cartago, e desempenha, nessa narrativa, um papel nuclear na medida em que a morte do sacerdote acaba por determinar a destruição de Tróia. A guerra parecia ter chegado ao fim, as naus gregas pareciam ter tomado o rumo de casa quando os troianos encontram um enorme cavalo de madeira abandonado na praia. Ao redor do artefato, deliberam sobre o melhor a fazer-se; de um lado da disputa está Timetes, cujo nome foi formado a partir do substantivo grego $\theta 0 \mu$ ós ("coração", "princípio da vontade, dos sentimentos e paixões"), defendendo que se leve a máquina para dentro das muralhas troianas. A ele se opõe Cápis, cujo nome deriva do substantivo latino caput ("cabeça", "razão") e que argumenta em favor da destruição do cavalo. Laocoonte, o sacerdote, vê todo o alvoroço do alto palácio: vale notar que ver de um ponto geograficamente mais alto é uma tópica de longa fortuna, que, freqüentemente, indica uma visão privilegiada. O sacerdote desce apressadamente e faz um discurso contra a enganosa máquina arquitetada pelo doloso Ulisses e construída por Epeu, e arremessa a sua lança contra o ventre do cavalo que escondia os melhores guerreiros gregos.

Como diz Enéias, se os Fados fossem favoráveis e os juízos não estivessem obstruídos, a reação de Laocoonte teria sido suficiente para convencer os troianos do perigo iminente e o palácio de Príamo ter-se-ia conservado; no entanto, os Fados lhe eram contrários. Em meio a tal confusão, pastores troianos trazem cativo um jovem desconhecido, o grego Sínon, que dá seqüência aos planos traiçoeiros dos aqueus ${ }^{7}$.

\footnotetext{
${ }^{6}$ Cf. Aristóteles. Retórica das paixões. Introdução, notas e tradução de Ísis Borges da Fonseca. São Paulo: Martins Fontes, 2003, II 1382 a 20.

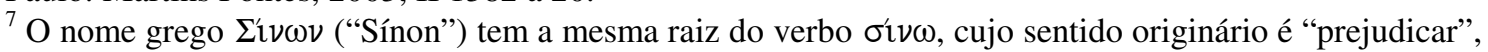
"causar dano", "domar"; e por extensão de sentido, "estragar", "destruir", "causar mal ao inimigo",
} 
Interrogado por Príamo, rei troiano, o jovem fingiu ter fugido dos gregos após desavenças com Ulisses, e contou que aquele enorme cavalo era um presente da armada grega à deusa Palas, construída na dimensão de um monte para que não pudesse ser levada para dentro das portas de Tróia, pois se isso ocorresse, a deusa passaria a favorecer o povo troiano. Se, diante desta argumentação, os troianos já estavam inclinados a acolher o cavalo, o fato que se segue acaba por persuadi-los definitivamente.

Enquanto Laocoonte sacrificava um touro no altar sagrado, duas enormes serpentes avançam rapidamente pelo mar, vindas da ilha de Tênedos em direção à praia de Tróia; chegando ao litoral, atacam os dois filhos de Laocoonte e, em seguida, investem contra o próprio sacerdote que corria em socorro da prole. A cena de dilaceramento e morte é descrita em detalhes vívidos, e faz-nos, de fato, vislumbrar o enorme horror sentido por todos aqueles que testemunharam o espetáculo. A morte de Laocoonte foi interpretada pelos troianos, naquele momento, como um castigo divino pela ofensa que o sacerdote cometera contra o presente destinado a Palas. Os troianos decidem, então, derrubar as muralhas intransponíveis em dez anos de guerra e conduzir o cavalo para dentro dos limites da cidade. Está determinado, então, o fim de Tróia.

A visão das serpentes e do ataque ao sacerdote e aos seus filhos é descrita como um acontecimento súbito, inesperado. $\mathrm{O}$ adjetivo empregado para qualificar o espanto que envolveu os espectadores daquela cena é improuidus (v. 200) - "que não previu", "que não estava preparado", "que fora surpreendido". Para reforçar essa idéia de imprevisto, Virgílio lança mão do advérbio ecce (v. 203), que neste passo equivale a "mas eis que, de repente" e, como assinala o canônico comentador Sérvio, mostra que o acontecimento se deu subitamente, o que amplifica a sensação de medo causada pela écfrase. Em seguida, o poeta emprega o adjetivo tranquilla (v. 203) para qualificar as águas do mar, criando assim um contraste entre a cena imediatamente anterior à chegada das serpentes e a cena que descreve o súbito aparecimento dos monstros marinhos. A descrição destes momentos de calma imediatamente anteriores ao horror contribuem para a criação de uma atmosfera de suspense e tensão.

Desde o início deste livro II, o poeta dá-nos indícios de um perigo iminente, e do efeito de temor que pretende provocar em seu auditório. Por diversas vezes, ao longo 
dos versos, encontramos o verbo latino horreo, "horrorizar-se" e seus derivados, assim como verbos, substantivos e adjetivos pertencentes ao mesmo campo semântico. Mas o efeito de terror pretendido pela cena é declarado manifestamente no começo do episódio, quando Enéias interrompe rapidamente a narrativa, há pouco iniciada, para introduzir o seguinte comentário: horresco referens, freqüentemente traduzido por "horrorizo-me só em referir".

De acordo com o Dicionário etimológico da língua latina de Ernout e Meillet, o primeiro sentido de horreo é "ter os pêlos do corpo eriçados", "arrepiar-se"; por extensão de sentido, "ser medonho", e ainda, "ter horror, temer". Portanto, como ressaltam os autores da Enciclopédia virgiliana no verbete dedicado a esse verbo, são dois os desenvolvimentos semânticos diretos possíveis a partir do sentido original: (1) alguma coisa tem o aspecto áspero, ou tem os pêlos eriçados, hirtos e por isso causa medo; (2) alguma coisa tem os pêlos eriçados porque sente medo. Esses dois valores são freqüentemente intercambiáveis na produção letrada latina. A partir disso, podemos interpretar este excurso de Enéias de duas maneiras complementares: (1) Enéias tem os pêlos do corpo hirtos apenas ao referir tal história, o que indica que causará pânico naqueles que o assistem; (2) Enéias tem os pêlos do corpo eriçados porque sente medo só em referir tal acontecimento. O herói, então, com o seu discurso, sente e também produz nos seus ouvintes o efeito causado pelo terror.

Assim, com a introdução desta oração, cuja ação principal é designada pelo verbo horreo, o poeta pretende referir a possibilidade de produção de uma sensação física dotada de repercussão afetiva. O poeta torna manifesto, então, o efeito que Enéias causaria na rainha Dido e nos demais ouvintes ao descrever a morte de Laocoonte, sobretudo com o emprego de recursos técnicos que confeririam a sensação não apenas de uma simples referência, mas da própria visão e experiência do acontecimento a que os ouvintes seriam submetidos por meio da clareza e vivacidade desta descrição, e que os coloca na posição de espectadores do que se vai narrar.

Virgílio inicia o verso que abre a écfrase com o advérbio hic (v. 199), que tem aqui um matiz temporal, indica simultaneidade do que se passará a contar, sendo freqüentemente traduzido por "agora", "nisto". Com a introdução desse advérbio, o poeta dá um primeiro indício de "presentificação" da cena, como se ela estivesse, de fato, acontecendo naquele momento, diante dos olhos de Dido, que ouve a narrativa, e 
também diante dos nossos olhos, leitores do poema. Mais adiante, há, por várias vezes, o emprego de um outro advérbio, iam, equivalente ao nosso "já", "agora" e desempenhando tanto a função de tornar presente o acontecimento narrado, quanto de assinalar o veloz movimento das serpentes cortando o mar e "já alcançando a praia" (v. 209), e já atacando o sacerdote e seus filhos. Este mesmo efeito é obtido pelo recorrente uso dos verbos no presente do indicativo. Ao longo de todo o episódio, as ações são narradas como se estivessem acontecendo no momento mesmo da narração. Para reforçar esse efeito, Virgílio faz uso da justaposição de sintagmas paratáticos.

Também a descrição física detalhada daqueles monstros faz com que o ouvinte ou o leitor tenham diante dos olhos a imagem concreta das aterrorizantes cobras do mar. Virgílio descreve-as como "serpentes de enormes anéis", angues immensis orbibus (v. 204), que avançam em turbilhão. Sobre a cabeça trazem "crinas vermelhas como sangue" (iubaeque sanguineae; v. 206-207); o adjetivo empregado para descrever as crinas é sanguineus, que significa "sanguinolento", isto é, "cor de sangue", mas também "feito de sangue", "ensangüentado", "sangrento", e, ainda, "que derrama sangue", "sanguinário", "cruel”. Este mesmo vocábulo é empregado na descrição dos olhos das serpentes, cuja tradução literal seria: "ardentes olhos tintos de sangue e fogo" (ardentisque oculos suffecti sanguine et igni - v. 210). ${ }^{8}$ Tanto o sangue quanto o fogo são elementos comumente relacionados a uma atmosfera de terror, pela força visual de que são dotados. Aos olhos ardentes, tintos de fogo e sangue, o poeta contrapõe o calafrio que a cena produz naqueles que a testemunham. $\mathrm{O}$ verbo horreo, empregado para designar o efeito desta descrição é, como se sabe, usado entre os poetas latinos, por extensão colateral de sentido, no lugar de algeo, literalmente "sentir frio", "ter calafrios".

À aplicação destes recursos, acrescenta-se ainda a descrição da vibração da língua das cobras, cuja construção verbal que a refere, quando pronunciada, obriga o leitor a reproduzir com a língua um movimento semelhante, exigido pela repetição de uma consoante líquida, o "l”:

\footnotetext{
${ }^{8}$ Odorico Mendes vertera o sintagma da seguinte maneira: “...E, em sangue e fogo tintos/ fulmíneos olhos..." - cf. Eneida Brazileira. 1854, v. 214-215 (edição disponível on-line em $<$ http://www.unicamp.br/iel/projetos/OdoricoMendes>).
} 
sibiL $\underline{\text { La Lambebant Linguis vibrantibus ora }}{ }^{9}$

Virgílio emprega também outros recursos fonéticos, como a aliteração, para assegurar a vivacidade da cena. Um exemplo claro deste recurso é a repetição da consoante "s" produzida no verso que descreve o violento avanço das serpentes pelo mar, em enormes turbilhões. O som resultante desta assonância remete à espuma do mar gerada pelo brusco movimento imposto às águas pelo deslizar das cobras:

\section{fit $\underline{\text { Sonitu}} \underline{S} \underline{\text { Spumante }} \underline{\text { Salo }}{ }^{10}$}

À visão dos monstros marinhos, dominada pela cor de sangue das crinas e dos olhos, mais uma vez o poeta contrasta o efeito causado por tal visão nos espectadores presentes: estão todos pálidos, sem cor, o adjetivo latino empregado é exsanguis, cujo primeiro sentido é "que não tem sangue", e por extensão, "que empalideceu”, "que perdeu a cor". Tais contraposições, como já foi dito, concorrem para o impacto visual produzido pela écfrase.

A terrível cena do ataque a Laocoonte e aos seus filhos dá seqüência à descrição da chegada das serpentes. Os monstros avançam primeiro contra os corpos das crianças, e lhes desferem dilacerantes mordidas. Em seguida, atacam o pai. De acordo com a precisa descrição, as cobras se enrolam por duas vezes no seu tronco, e com mais duas voltas envolvem o seu pescoço; as cabeças investem contra ele, mordendo-o e dilacerando-o. Em vão, Laocoonte tenta, com as mãos, desfazer os nós que lhe prendem. Como é possível notar, a pintura é, mais uma vez, forte e minuciosa; cada parte cuidadosamente detalhada, visando, a todo momento, a produção do efeito de terror.

Também o episódio camoniano mostra-se abundante no emprego dos recursos técnicos descritivos, aplicados com grande engenho pelo poeta com vistas à criação de um mesmo cenário de terror. Os gigantes constituem uma tópica épica estabelecida, inaugurada pelo ciclope Polifemo na Odisséia de Homero. O Adamastor está inserido nesta consuetudo da maldição épica feita aos navegantes pelo vencido, e que teve início

\footnotetext{
9 Cf. Virgílio. Eneide. A cura di Ettore Paratore, traduzione di Luca Canali. Milano: Lorenzo Valla/Arnoldo Mondadori Editore, s.d., v. 211 (em trad. de Manuel Odorico Mendes, op. cit., 1854, v. 215-216: “...Com vibradas línguas/ vinham lambendo as sibilantes bocas”).

${ }^{10}$ Cf. Virgílio, op. cit., s.d., v. 209. Literalmente: "Fez-se um estrondo no salso mar espumante" (minha tradução). O poeta Odorico Mendes assim traduzira este verso: "Soa espumoso o páramo salgado" (op. cit., 1854, v. 213).
} 
com a imprecação de Polifemo contra Odisseu. ${ }^{11} \mathrm{O}$ gigante camoniano é construído como uma figura ameaçadora, que anuncia aos portugueses as punições que o futuro lhes reserva, em paga da ousadia e atrevimento cometidos no descobrimento de uma nova rota marítima para a Índia. A introdução desta tópica n'Os Lusíadas já indica, antes mesmo da sua descrição detalhada, a atmosfera terrível que se pretende compor também nesta écfrase.

O episódio da aparição do gigante Adamastor à armada portuguesa está igualmente inserido numa narrativa mais ampla que o herói Vasco da Gama é instado a fazer ao rei de Melinde. As naus vinham cortando os mares do sul da África, os ventos sopravam prosperamente quando, numa noite, estando os marinheiros descuidados, subitamente aparece "uma nuvem que os ares escurece", e envolto nela, surge a enorme figura de um gigante. É o prelúdio da tempestade enfrentada na passagem do Cabo da Boa Esperança, trabalhada metaforicamente na prosopopéia do gigante.

O adjetivo "descuidado", empregado por Camões para qualificar o estado dos marinheiros no momento da aparição do gigante, tem valor semântico equivalente ao adjetivo latino improuidus aplicado por Virgílio para descrever a surpresa com que os troianos assistiram ao ataque das serpentes. Como já fora mencionado acerca da descrição virgiliana, também aqui o poeta assinala o modo súbito e inesperado com que se dá o surgimento do gigante, de modo a reforçar a sensação de medo que será produzida por esta cena. Apenas três versos adiante, o poeta torna isto manifesto, quando põe na boca do Gama os seguintes versos para qualificar a negra nuvem:

Tão temerosa vinha e carregada, que pôs nos corações um grande medo; $;^{12}$

Na estância posterior, Vasco da Gama dá início ao detalhamento do conjunto do seu objeto, trata-se de uma figura vigorosa e robusta, de disforme e grandíssima estatura. Os adjetivos colhidos para descrever a compleição física de Adamastor reforçam o aspecto pavoroso do gigante, desprovido de um corpo bem proporcionado, e dotado de uma aspereza, que a exemplo dos pêlos hirtos de Enéias, causam grande horror. Traz o rosto irado e a barba comprida, hirta e suja. Os olhos fundos e a postura

${ }^{11}$ Quint, David. The epic curse and Camões' Adamastor. In: Epic and empire. Princeton, N.J.: Princeton University Press, 1993. Pte. II, cap. 3.

${ }^{12}$ Cf. de Camões, Luís. Os Lusíadas. Comentados por Augusto Epifânio da Silva Dias. Rio de Janeiro: MEC, 1972 (canto V, estância 38, v. 1-2). 
"medonha e má", a boca "negra" e os dentes "amarelos". Tinha a cor baça da terra. Este amplo conjunto de adjetivos acaba por pintar com cores escuras as horripilantes formas do gigante; assim como o fogo e o sangue, o negrume e a escuridão estão freqüentemente relacionados a uma atmosfera terrível. A descrição física do monstro é concluída na estância seguinte, com a ênfase do Gama na grandeza desmedida de seus membros, e na dissonância da sua rude voz:

C'um tom de voz nos fala horrendo e grosso, que pareceu sair do mar profundo. ${ }^{13}$

A enumeração das particularidades do gigante é feita ao longo de dezesseis versos, os adjetivos empregados descrevem as minúcias do seu aspecto pavoroso de forma tão vívida e precisa, que parecemos tê-lo diante dos olhos. Para reforçar a "presentificação" desta visão, Camões faz uso abundante do presente histórico; mas neste episódio, é a prosopopéia que surge como recurso fundamental para a produção do terror. Terminada a descrição física do gigante, o poeta lança mão da apóstrofe, e faz com que aquela figura gigantesca, transformada em monte pelos deuses do Olimpo (castigo infringido por sua participação na Titanomaquia), dirija aos portugueses uma imprecação profética, em discurso direto, que tornando a cena ainda mais vívida e presente, amplifica ainda mais o efeito de temor produzido pela écfrase.

A vivacidade da cena é também assegurada pelo emprego de recursos fonéticos, um exemplo manifesto é o verso que descreve o barulho do mar no instante do surgimento do gigante. Com a aliteração em "r", o poeta busca reproduzir o estrondoso som das ondas no mar tempestuoso:

Bramindo o negro mar de longe brada, como se desse em vão nalgum rochedo. ${ }^{14}$

Mas assim como fizera Virgílio no episódio de Laocoonte, Camões também assinala de forma declarada o efeito que a cena descrita pretende causar; e os versos camonianos parecem constituir uma tradução perifrástica daquele horresco referens pronunciado por Enéias no início da sua narrativa. Terminada a descrição da pavorosa figura, afirma Vasco da Gama:

\footnotetext{
${ }^{13}$ Cf. de Camões, op. cit. (canto V, estância 40, v. 5-6).

${ }^{14}$ Cf. de Camões, op. cit. (canto V, estância 38, v. 3-4).
} 
Arrepiam-se as carnes e o cabelo,

a mi e a todos, só de ouvi-lo e vê-lo. ${ }^{15}$

O primeiro verso, "arrepiam-se as carnes e o cabelo", é, como vimos, uma perífrase de horresco. Para verter o verbo refero, empregado por Virgílio para designar a descrição que seria feita por Enéias, Camões lança mão dos verbos ouvir e ver, evidenciando assim que a écfrase permite ao leitor certa experimentação visual e auditiva do acontecimento narrado. A produção da clareza e vivacidade por meio de recursos técnicos fornecidos pela linguagem, que gera no leitor a sensação de visão e audição da cena descrita, permite, através de um procedimento exclusivamente verbal, a manifestação ficcional de um afeto. Nesse sentido, assim como a pintura foi considerada uma espécie de poesia silenciosa, da mesma maneira a écfrase, ou descrição, foi tida como uma pintura que fala aos nossos ouvidos. E falando aos nossos ouvidos, como fizera Virgílio, Camões evidencia a emulação do seu modelo maior e alinha-se na fileira das grandes auctoritates épicas.

\section{Referências Bibliográficas}

ALVES, Hélio. Camões, Corte-Real e o sistema da epopéia quinhentista. Acta Universitatis Conimbrigensis. Coimbra, 2001.

ARISTÓTELES. Retórica das paixões. Introdução, notas e tradução de Ísis Borges da Fonseca. São Paulo: Martins Fontes, 2003.

Ars rhetorica. Recognouit breuique adnotatione critica instruxit W. D. Ross. Oxford: University Press, 1959.

BARCHIESI, Alessandro. Ecphrasis. In: MARTINDALE, C. (org.). The Cambridge companion to Virgil. Cambridge: University Press, 1997. p. 271- 281.

BENVENISTE, Émile. O vocabulário das instituições indo-européias. Campinas: UNICAMP, 1995. Tomo II.

de CAMÕES, Luís. Os Lusíadas. Comentados por Augusto Epifânio da Silva Dias. Rio de Janeiro: MEC, 1972.

\footnotetext{
${ }^{15}$ Cf. de Camões, op. cit. (canto V, estância 40, v. 7-8).
} 
CICERO. De natura deorum. Academica. With an English translation by $\mathrm{H}$. Rackham.Loeb Classical Library. Cambridge, Mass./ London: Harvard University Press, 1994.

De partitione oratoria. With an English translation by H. Rackham. Cambridge, Mass./ London: Harvard University Press, 1977.

CURTIUS, E. R. Literatura europea y edad media latina. Madrid: Fondo de Cultura Económica, 1955. Tomo I.

Enciclopedia virgiliana. Roma: Istituto della enciclopedia italiana fondata da Giovanni Treccani, 1988. Vol. II.

ERNOUT, A.; MEILlET, A. Dictionnaire étymologique de la langue latine. Paris: Klincksieck, 1967.

GINZBURG, Carlo. Écphrasis e citação. In: A micro-história e outros ensaios. Lisboa: Difel, 1989. Cap. 8, p. 215-232.

LAUSBERG, Heinrich. Manual de retorica literaria. Madrid: Gredos, 1975. Tomo II.

MORGANTI, Bianca F. A Mitologia n’Os Lusíadas: balanço histórico-crítico. Campinas: $2003 \quad$ (disponível on-line em $<$ http://libdigi.unicamp.br/document/?code=vtls000317263>).

MENDES, Manuel Odorico. Eneida Brazileira. 1854 (edição disponível on-line em $<\mathrm{http}: / /$ www.unicamp.br/iel/projetos/OdoricoMendes $>$ ).

PASCHALIS, M. Virgil's "Aeneid": semantic relations and proper names. Oxford: Clarendon Press, 1997.

PÉCORA, Antonio Alcir B. Máquina de gêneros. São Paulo: Edusp, 2001.

PIVA, Luís. O quinto canto de Os Lusíadas visto por Manuel Pires de Almeida. Revista camoniana. Centro de Estudos Camonianos da USP. São Paulo, $2^{\mathrm{a}}$ Série, vol. 1, p. 5966, 1978.

QUINT, David. The epic curse and Camões' Adamastor. In: Epic and empire. Princeton, N.J.: Princeton University Press, 1993. Pte. II, cap. 3, p. 99-130. 
QUINTILIEN. Institution oratoire. Texte revu et traduit, avec introduction et notes, par Henri Bornecque. Paris: Garnier, s.d.

de SENA, Jorge. Estudos sobre o vocabulário de "Os Lusíadas": com notas sobre o humanismo e o exoterismo de Camões. Lisboa: Edições 70, 1982.

A estrutura de "Os Lusíadas" e outros estudos camonianos e de poesia peninsular do século XVI. Lisboa: Edições 70, 1980.

VIRGÍlIO. Aeneis. Edição anotada pelo Pe. Arlindo Ribeiro da Cunha. Braga: Livraria Cruz, 1945.

. A Eneida. Trad. de Manuel Odorico Mendes. Paris: Rignoux, 1854.

. Eneide. A cura di Ettore Paratore, traduzione di Luca Canali. Milano: Lorenzo Valla/Arnoldo Mondadori Editore, s.d.

Eneide: libro secondo. Introduzione, commento e note di Remigio Sabbadini, revisione di Concetto Marchesi.Torino: Loescher, 1985. 